\title{
Yielding of a quartz sand from saturated to dry state
}

\author{
Vincenzo Butticè ${ }^{1, *}$, Alessio Ferrari ${ }^{1,2}$, and Marco Rosone ${ }^{1}$ \\ ${ }^{1}$ Dipatimento di Ingegneria - DI, Università degli Studi di Palermo, 90133 Palermo, Italy \\ ${ }^{2}$ Ecole Polytechnique Fédérale de Lausanne, Laboratory of Soil Mechanics, 1015 Lausanne, Switzerland
}

\begin{abstract}
The paper presents the results of an experimental work where we analyse the behaviour of an unsaturated quartz sand in a wide range of degree of saturation (from saturated to dry state). The possibility of anticipating the hydro-mechanical behaviour of the soils when they approach the dry state is fundamental in many areas. An extensive experimental program, including controlled-suction and constant water content oedometric tests, was carried out to deeply analyse the water retention behaviour and the relationship between the yield stress and suction (Loading-Collapse curve). All elasto-plastic models provide a monotonically increase of the yield stress with suction. This assumption implies that the yield stress in the dry state is larger than the one relative to the saturated state, in contrast with the classical geotechnical points of view, which suggest that the yield stress of dry granular material must be approximately the same as that of the saturated one. The obtained results show that the yield stress of the sand does not increase monotonically with the suction, as predicted by commons models. In fact, the Loading - Collapse curve showed in this work presents a maximum point, and the yield stress for saturated condition is almost the same of the dried one.
\end{abstract}

\section{Introduction}

Granular materials are involved in many civil engineering applications. For instance, the base and subbase layers of low traffic pavements are made of gravels or sands. These layers are generally in unsaturated conditions and the suction influences drastically their hydro-mechanical behaviour [1-3].

The effects of the suction on shear strength (e.g. [45]) and hydraulic conductivity (e.g. [6]) of the sands are well-known in literature, however few researches focus on their volumetric behaviour in the unsaturated state. In particular, a very small number of determinations of the yielding behaviour of unsaturated sandy soils are available in the literature (e.g. [7-10]).

The assessment of the yielding behaviour in unsaturated conditions allows to predict and prevent the possible occurrence of plastic strains under various environmental conditions. In particular, the capability of anticipating the hydro-mechanical behaviour of sandy soils when they approach the dry state is fundamental in the areas classified as arid or sub-arid zone - like the Mediterranean area - in which evaporation during the summer could cause the complete dryness of the soil. Classical Soil Mechanics approach would anticipate the behaviour of a dry sandy soil to be similar to the saturated one, providing that the hydro-mechanical response is described in terms of effective stress.

Donald [5] indeed has shown that the available shear strength of unsaturated sandy soils tends, after an initial increase, to the shear strength in saturated conditions once suction increases significantly.

A similar behaviour should be expected also for the evolution of the yield stress with suction, but - to the authors' knowledge - such evidence has not been provided yet.

Most elasto-plastic models that describe the volumetric behaviour of unsaturated soils, formulated both in terms of mean net stress (e.g. [11-16]) or effective stress (e.g. [17-19]) introduce the LoadingCollapse curve (LC). These frameworks provide - for a given value of cumulated volumetric plastic strain - a monotonically increase of the yield stress with suction. This assumption implies that the yield stress in the dry state is the maximum possible value and, in particular, it is larger than the one relative to the saturated state.

To shed light on this aspect, in this paper an experimental work is presented in order to verify the evolution of the LC curve for a quartz sand over the entire range of degree of saturation.

\section{Material and methods}

\subsection{Tested material and specimen preparations}

The quartz sand used in this research is a pre-washed uniform sand $\left(\mathrm{C}_{\mathrm{u}}=1.4 \div 1.6\right)$ with grain size in the range of $0.07-0.85 \mathrm{~mm}$ (Fig.1). The specific gravity is 2.65 .

Corresponding author: vincenzo.buttice@unipa.it 
The experimental programme presented in this paper includes the determination of the water retention behaviour along with the execution of controlled-suction and constant water content oedometric tests. The target initial void ratio was 0.77 .

The specimens for the controlled-suction oedometric tests and for the determination of the water retention behaviour were prepared in saturated conditions by wet pluviation in de-aired water. Air-dry sand was uniformly rained through a funnel placed above a steel ring filled with water.

Sand raining was performed in steps in order to verify the uniformity of the distribution inside the ring. At the end of the procedure, each sand layer was levelled and the height of the sample was measured, to verify the achieved void ratio [20].

The specimens used in the controlled-suction oedometric cell were $11 \mathrm{~mm}$ high and $33 \mathrm{~mm}$ in diameter, while the specimens used to determine the soil water retention curve were $20 \mathrm{~mm}$ high and $60 \mathrm{~mm}$ in diameter.

The specimens for the constant water content tests were prepared by moist-tamping at the same target void ratio. Three layers of sand were compacted in a steel ring (diameter $56 \mathrm{~mm}$, height $20 \mathrm{~mm}$ ). To minimize the evaporation phenomenon during the preparation, the moisturized sand necessary for each layer was stored in tiny hermetically closed glass jars [21]. Sand was poured in small quantities ( $25 \mathrm{~g}$ maximum) to obtain a uniform spreading. At the end of the compaction of the latter layer, the height of the specimen and the regularity of the surface were verified to minimize the roughness of the surface which could cause stress densification and result in grains' crushing.

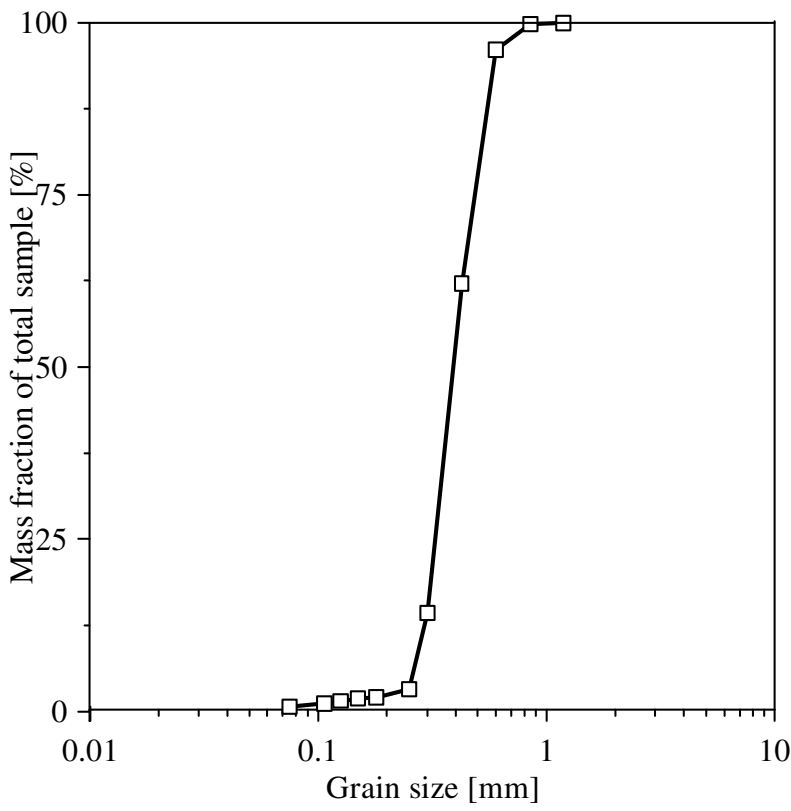

Fig. 1. Grain size distribution curve of the quartz sand used in the experiments.

\subsection{Controlled-suction tests}

Controlled-suction oedometers were used in order to determine the main drying water retention curve and to quantify the evolution of the yield stress with suction. Matric suction control was achieved using the negative water column technique (Fig. 2).

A cellulose microporous membrane with a thickness of $0.1 \mathrm{~mm}$, pore size of $0.45 \mu \mathrm{m}$ (corresponding air entry value of $250 \mathrm{kPa}$ ) and permeability of $2 \cdot 10^{-8} \mathrm{~m} / \mathrm{s}$ was used as high-air-entry-value filter.

The membrane was put between the soil and the bottom drainage plate of the apparatus, connected to the burette used to impose the negative pore water pressure.

To determine the water retention curve, the suction was increased starting from the saturated state maintaining a constant vertical stress of $1.75 \mathrm{kPa}$.

Suction was increased in steps following a geometric series. Each suction equalization phase was considered ended when no more variations of the water level in the burette and no more settlements were registered

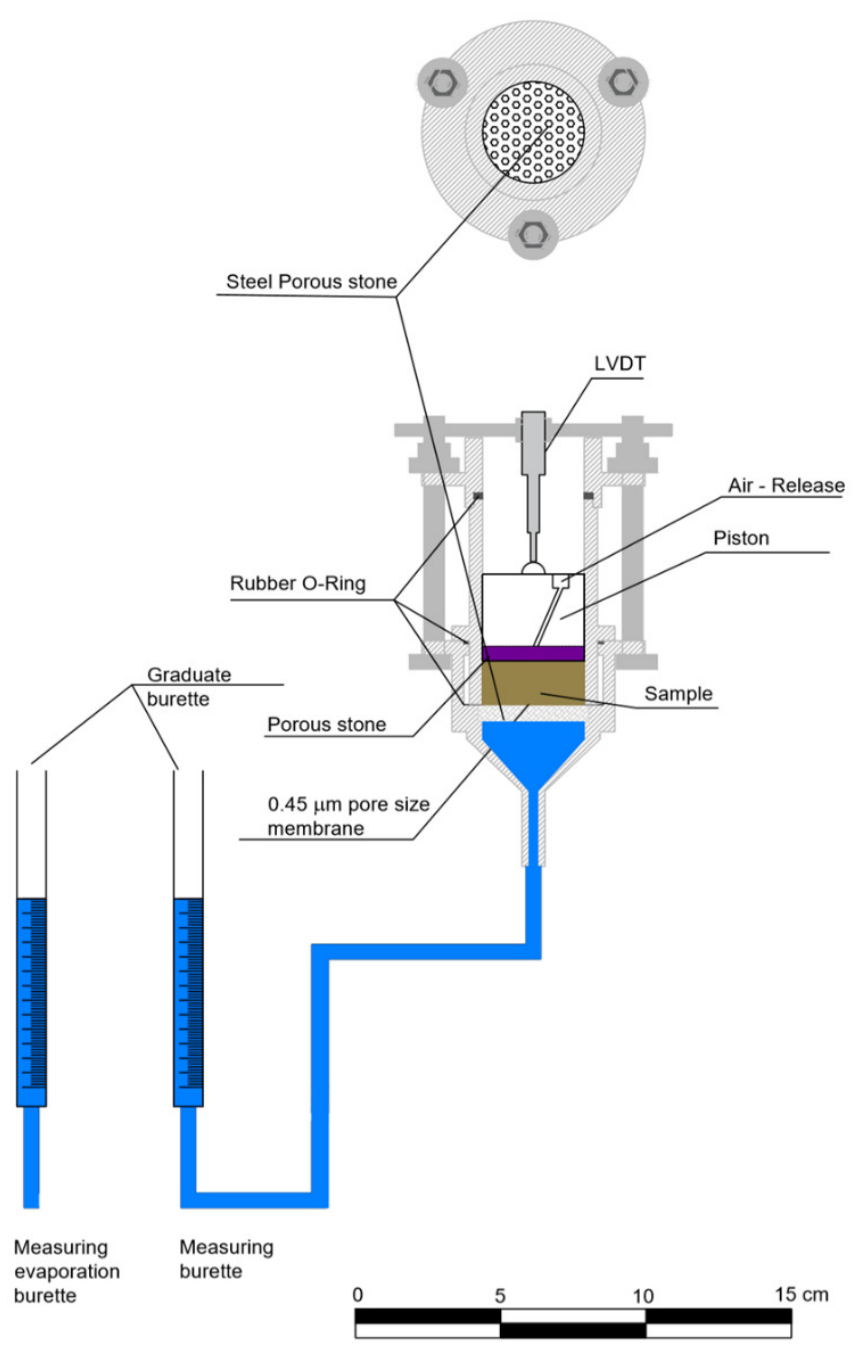

Fig. 2. Experimental set-up of the controlled-suction oedometric cell operating with the negative water column technique. 
Water volume changes of the specimens were monitored through the burette (resolution of $\pm 0.7 \%$ ). Vertical displacements were measured with a resolution of $1 \mu \mathrm{m}$ and corrected accounting for the deformation of the apparatus. However, no relevant variation of void ratio was measured during the imposed drying path.

The same apparatus was used to measure the evolution of the yield stress with suction. Nine controlled-suction tests were performed by applying the vertical stress with a dead-weight loading frame.

The load was increased in steps from a minimum of $30 \mathrm{kPa}$ to a maximum of $12 \mathrm{MPa}$.

The water content changes of the specimens were monitored through the burette, which position was continuously adjusted in order to maintain a constant value of imposed suction. To take into account the contribution of evaporation and to correct the results, a second monitoring burette was used.

All tests were conducted in a controlled-temperature room $\left(\mathrm{T}=21^{\circ} \mathrm{C}\right)$; the relative humidity of the room was monitored (average $\mathrm{RH}=40 \%$ ).

\subsection{Constant water content oedometric tests}

Nineteen complementary oedometric tests at constant water content were also conducted. Water contents were in the range of $2.35 \div 21.35 \%$. Specimens were installed in conventional oedometric cells using two impermeable confining disks. In addition, the entire cells were isolated from the external environment by means of an impermeable membrane. Five samples were prepared using a dry sand. For these samples a suction of 16.6 $\mathrm{kPa}$, corresponding to the residual degree of saturation, was assigned.

The load was increased in steps, and the maximum vertical total stress applied was 6.0 MPa. The water content was measured both at the beginning and at the end of each test, in order to verify that no significant evaporation had occurred. The maximum variation of the measured water content was less than $0.4 \%$. During these tests the computed variations of the degree of saturation were small (in the order of $0.3 \div 4.9 \%$ ), so that they can be considered as quasi-constant degree of saturation tests.

\section{Experimental Results}

The main drying water retention curve of the tested soil is depicted in Fig. 3 in terms of degree of saturation $\left(S_{r}\right)$ vs matric suction $(s)$. The experimental points were fitted using the expression [22]:

$$
S_{r}=S_{r, r e s}+\frac{1-S_{r, r e s}}{\left[1+(\alpha s)^{n}\right]^{m}}
$$

where $S_{r, \text { res }}$ is the residual degree of saturation (equal to 0.01$), \alpha$ is a fitting parameter related to inverse of airentry value and $n$ and $m$ are fitting parameters.
The best-fitting was obtained with the parameters $\alpha=0.46 \mathrm{kPa}^{-1}, n=3.38, m=0.74$ and $S_{r, r e s}=0.01$.

Figure 4 depicts the results of five controlled-suction oedometric curves. The curves refer to the saturated state ( $\mathrm{s}=0)$, unsaturated states $(s=4,5$ and $9 \mathrm{kPa})$ and to the dry condition ( $\left.s=16.6 \mathrm{kPa}, S_{r}=0.01\right)$.

The performed tests allow to follow the evolution of the yield stress with suction.

Atkinson [23] suggests the use of the term yielding only to describe the end of the elastic range, according to the classical meaning of yielding in plasticity.

The yield stress of a granular soil does not depend only on the maximum effective vertical stress that the soil has sustained in the past, but it is strictly linked to the relative density.

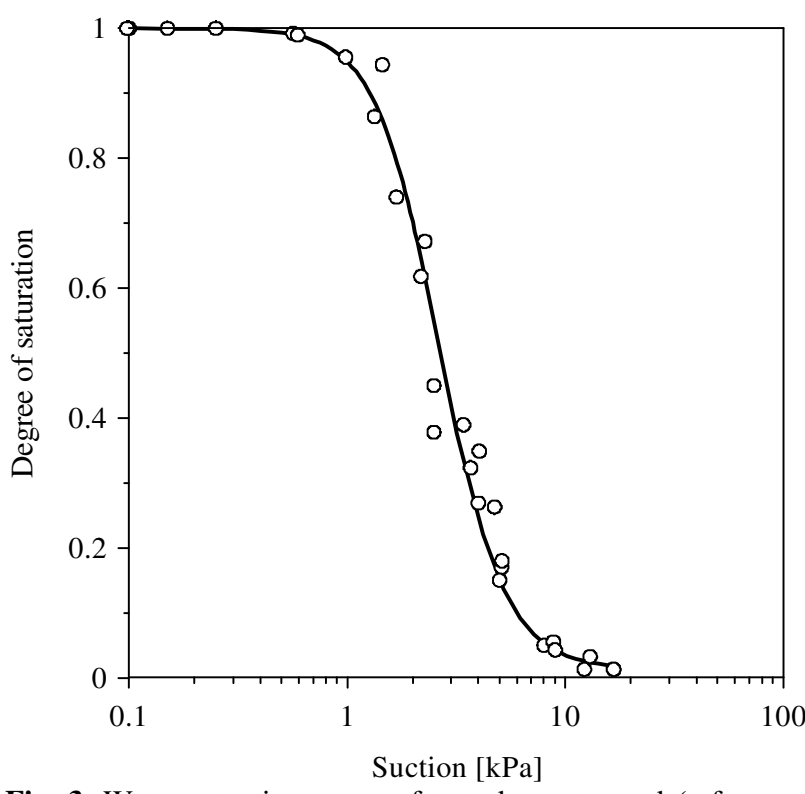

Fig. 3. Water retention curve of tested quartz sand (reference void ratio $\mathrm{e}=0.77$ ).

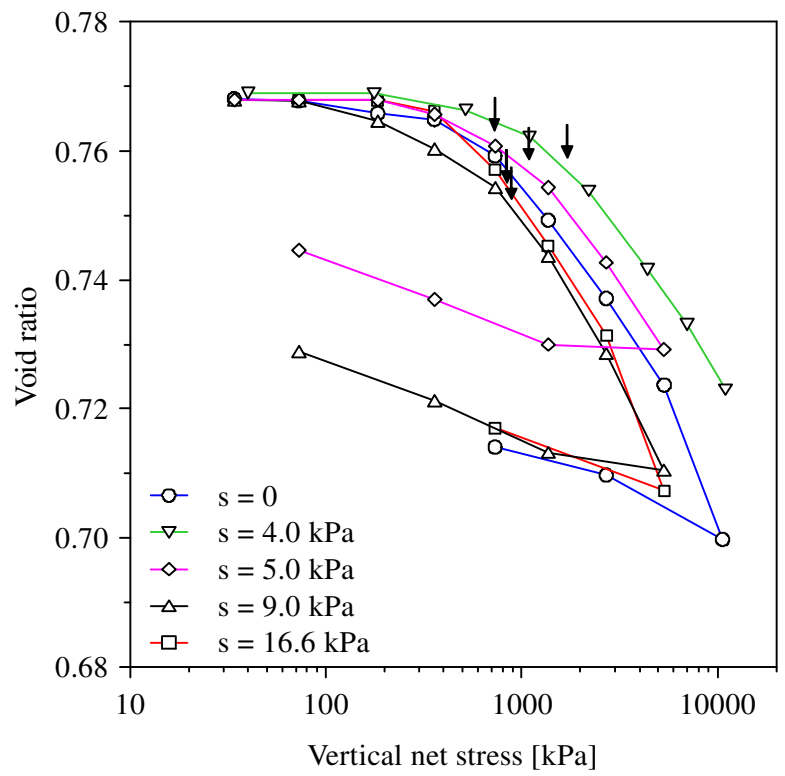

Fig. 4. Selected controlled suction oedometric curves of quartz sand in term of vertical net stress. 
As known, it is possible to reach a very high value of relative density without a direct compaction (e.g. vibrating the sample).

In the explored range of confining stress (up to 12 $\mathrm{MPa}$ ), the yielding mechanism is expected to be associated mainly to particle rearrangement [24-28]. Grain crushing is limited as shown in Fig. 5, in which the grain size distributions of two tested specimens (maximum vertical stresses of 6 and $12 \mathrm{MPa}$ ) are compared with the initial one.

The yield stress may be obtained from the oedometer tests using different approaches such as Casagrande's method, the bi-logarithmic method [29] or the incremental method [30].

Boone [31], reviewing the various methods, noted that Casagrande's method was susceptible to scaling issues, leaving some ambiguity in the interpretation of results and proposed an alternative mathematical and graphical method using the Recompression Index and the maximum Compression Index.

The advantages of Boone's method can be summarised as: (i) it is based on simple slope-intercept mathematics, (ii) it is independent of plotting scale and (iii) it does not require graphical interpretation [31].

For all these reasons the Boone's method was used in this work.

Figure 6 depicts, in the plane vertical net stress against suction, the yield points identified on the obtained oedometric curves.

The suctions for the constant water content tests were determined using the water retention curve using the average degree of saturation of the test; to this regard, it is worth to observe that since the retention curve is subvertical in the range of the degree of saturation explored with the constant water content tests, small errors in the determination of the degree of saturation do not cause significant errors in the determination of the suction.

The results in Figure 6 show that the yield stress does not increase monotonically with the suction. After an initial increase, a maximum of the yield stress is observed, followed by a continuous decrease until the dry condition is reached. The yield stress at saturated condition is almost the same of the yield stress at dry state. This trend is consistent with the ones observed for other geotechnical properties of unsaturated sands (i.e. shear strength and hydraulic conductivity) [4-6].

Previous Loading-Collapse curves determined experimentally for a variety of soils by different authors show a monotonic increase of the yield stress with suction (e.g. [10, 12, 14, 32-37]). Probably, this could be due to a lack of experimental yield points determined at low degrees of saturation.

\section{Summary and conclusion}

The paper showed the results of an extended experimental campaign (nine controlled-suction oedometric tests and nineteen constant water content oedometric tests) aimed at assessing the evolution of the yield stress of a quartz sand from the saturated condition to the dry state.

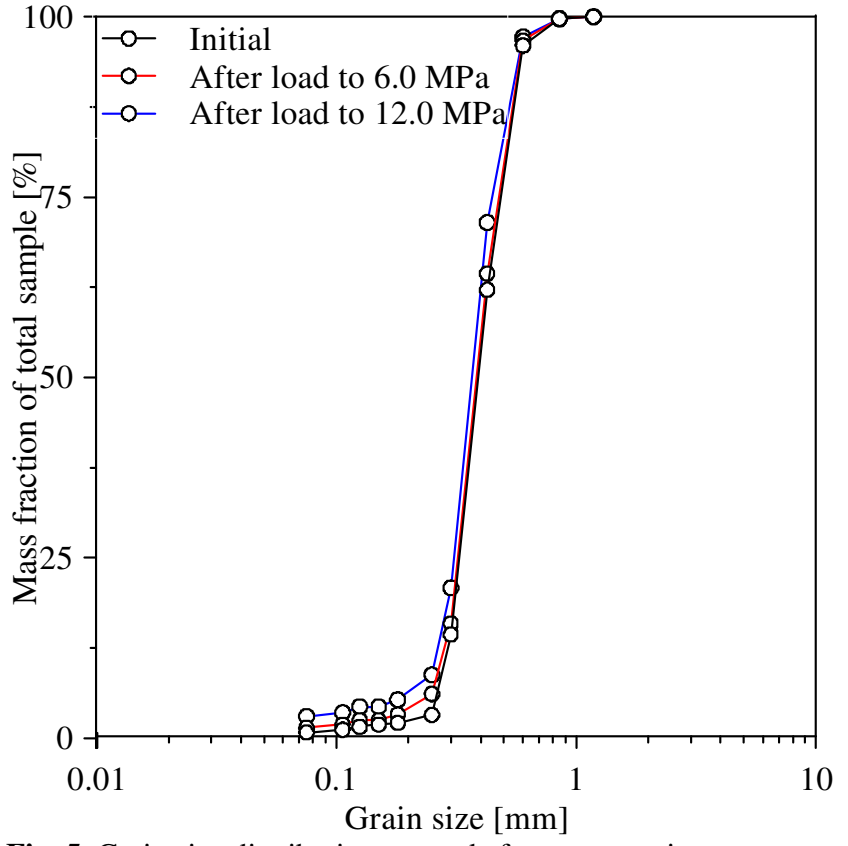

Fig. 5. Grain size distribution pre and after compression

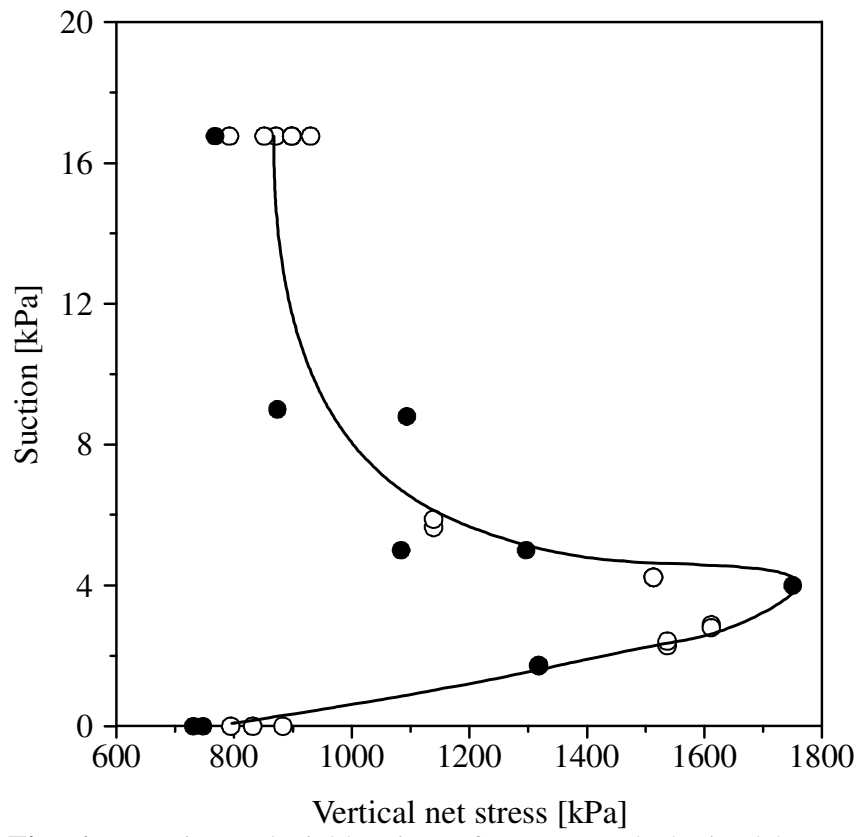

Fig. 6. Experimental yield points of quartz sand obtained by constant water content tests (white points) and controlled suction tests (black points)

The evolution of the yield stress at different suction levels was quantified and it has been shown that, in contrast with what foreseen by the classical elasto-plastic models for unsaturated soils, it does not increase monotonically with suction.

In fact, the obtained Loading - Collapse curve presented a maximum point, and the yield stress for saturated condition is almost the same of the dried one. Such a behaviour should be included in the constitutive models which aim at describing the soil behaviours at low degrees of saturation. 


\section{References}

1. H. Nowamooz, C. Chazallon, M. I. Arsenie, P. Hornych, F. Masrouri, Comput. Geotech. 38, 4, 491503 (2011)

2. X. N. Ho, H. Nowamooz, C. Chazallon, B. Migault, Road Mater. Pavement. 15, 3, 642-658 (2014)

3. X. N. Ho, H. Nowamooz, C. Chazallon, B. Migault, Int. J. Pavement. Eng. 16, 9, 842-856 (2015)

4. A. W. Bishop, I. B. Donald, 5th Int. Conf. Soil Mech., Paris, France. 13-22 (1961)

5. I. B. Donald, 2nd Australia - New Zealand Conf. Soil Mech. Found Eng. Christchurch, New Zealand. 200-205 (1956)

6. Y. Lins, T. Schanz, Unsaturated Soils: Experimental Studies. Springer Proceedings in Physics (Ed T. Schanz) 93, Springer, Berlin, Heidelberg (2005)

7. O. M. Vilar, R. A. Rodrigues, Can. Geotechnic. J. 48, 226-233 (2011)

8. A. P. Das, T. Thyagaraj, Int. J. of Geotechnical Engineering (2016)

9. E. C. Lawton, R. J. Fragaszy, J. H. Hardcastle, ASCE J. of getech. Eng. 115, 9, 1252-1267, (1989)

10. A. Ferrari, J. Eichenberger and L. Laloui, Geotechnique 63, 11, 1433-1446 (2013)

11. E. E. Alonso, A. Gens, A. Josa, Geotechnique 40, 3 (1990)

12. S. J. Wheeler, V. Sivakumar, Geotechnique 46, 1 (1995)

13. D. A. Sun, H. Matsuoka, Y. P. Yao, W. Ichihara, Soils Found. 40, 3 (2000)

14. D. A. Sun, H. Matsuoka, H. B. Cui, Y. F. Xu, Int. J. Numer. Anal. Meth. Geomech. 27, 1079-1098 (2003)

15. C. Rampino, C. Mancuso, F. Vinale, Can. Geotechnic. J. 37, 748-763 (2000)

16. K. Georgiadis, D. M. Potts, L. Zdravkovic, Geotechnique 53, 1 (2003)

17. S. J. Wheeler, R. S. Sharma, M. S. R. Buisson, Geotechnique 53, 1 (2003)

18. W. Sun, D. Sun, J. Li, Experimental and Apllied Modeling of Unsaturated Soils, GeoShangai 2010 International Conference ASCE (2010)

19. M. Nuth, L. Laloui, 3rd Asian Conference on Unsatureted soils (UNSAT-ASIA 2007) Nanjing, China (2007)

20. M. E. Raghunandan, A. Juneja, B. C. Benson Hsiung, Int. J. of Geotech. Eng. 6, 125-131 (2012)

21. J. D. Frost, J.-Y. Park, J. Geotechnical Testing 26, 1 (2003)

22. M. T. Van Genuchten, Soil Sci. Soc. Am. J. 44, 5 (1980)

23. J. H. Atkinson, Proceedings of the conference on Engineering Geology of Weak Rock, Leeds, (J. M. Cripps, J. M. Coulthard, M. G. Culshaw, A.
Forester, S. R. Hencher and C. F. Moon. (eds)). Balkema, Rotterdam. 150 (1990)

24. P. R. Vaughan, 2nd International Conference on Geomechanics in Tropical Soils, Singapore, Balkema, Rotterdam, 2, 469-87 (1988)

25. G. Mesri, B. Vardhanabhuti, Can. Geotech. J. 46, 369-392 (2009)

26. M. R. Coop, I. K. Lee, C. P. Wroth Memorial Symposium: Predictive soil mechanics, London, 186-198 (1993)

27. G. R. McDowell, M. D. Bolton, Géotechnique, 48, 5, 667-679 (1998)

28. Y. Nakata, M. Hyodo, A. F. L. Hyde, Y. Kato, H. Murata, Soil and Foundation 41, 2, 39-51 (2001)

29. R. Butterfield, Géotechnique, 29, 5 (1979)

30. D. E. Becker, J. H. A. Crooks, K. Been, M. G. Jefferies, Can. Geotechnic. J. 24, 4, 549-564 (1987)

31. S. J. Boone, Can. Geotechnic. J. 47, 3, 281-296 (2010)

32. A. Maatouk, S. Leroueil, P. La Rochelle, Géotechnique, 45, 3, 465-477 (1995)

33. R. S. Sharma, Mechanical behaviour of unsaturated highly expansive clays (University of Oxford, England. Ph.D. thesis, 1998)

34. T. M. Thu, H. Rahardjo, E. Leong, Can. Geotechnic. J. 44, 226-275 (2007)

35. S. Leroueil, P. S. Barbosa, Unsaturated soils for Asia. Proceedings of the Asian Conference on Unsaturated Soils, UNSAT-Asia 2000, Singapore, 18-19 May, (2000)

36. O. M. Vilar, R. A. Rodrigues, Can. Geotechnic. J. 48, 226-233 (2011)

37. C. Airò Farulla, A. Ferrari, E. Romero, Can. Geotechnic. J. 47, 6, 688-703 (2010) 